\title{
Mapwork.education: online adaptive system for cartographic education
}

\author{
Martin Hanus ${ }^{a}$,, Lenka Havelková a $^{\text {, Veronika Bernhäuserová a }}{ }^{\text {, Kristýna Štolcová a }}$ \\ ${ }^{a}$ Charles University, Faculty of Science, Centre for Geographical and Environmental Education, martin.hanus@natur.cuni.cz, \\ l.havelkova@natur.cuni.cz,veronika.bernhauserova@natur.cuni.cz,kristyna.stolcova@natur.cuni.cz \\ * Corresponding author
}

Keywords: Cartographic education, Map use, Online tool, Secondary education, Educational technologies

\begin{abstract}
:
We live in a visual era where society prefers data presented in a visual form rather than as a text. As a result, the use of maps, i.e., visual representations of spatial information, increases. Given that, maps are (also due to the development of cartography) widely used not only by geographers but also by the general public. Moreover, the public not only uses maps but, thanks to the availability of diverse data and user-friendly GIS apps, also creates them. The frequency with which maps are used (and also misused), as well as the fact that their authors are no longer only trained and professionally skilled cartographers, then bring the necessity of a higher accent on cartographic education. Specifically, the development of map skills. Only with fully mastered map skills can students recognize the power that maps have and appropriately adapt their conclusions, predictions, and decisions.
\end{abstract}

For that reason and for fully using the educational potential of maps, it is necessary to develop not only map reading but also cognitively more demanding map skills in students. Previous studies in the field distinguish three main types of map use skills, i.e., map reading, map analysis, and map interpretation, based on which individual operations with maps are classified. Distinguishing the main types of map skills, structuring them into a hierarchical cognitive model, and specifying their knowledge/operational components is fundamental for the development of effective learning and teaching systems.

In addition to the distinct cognitive complexity of map skills, teachers should consider individual differences in students' map skills level and the ideal way of map skills development during lessons. However, the development of (cognitively more demanding) map skills itself is considered challenging, let alone a development that is systematic and tailored to individual needs of students. Many secondary teachers call for more methodological and practical tools as a support. Therefore, the research group from the Centre for Geographical and Environmental Education at Charles University (Czechia) reflected this need together with the new perspectives opened by the dispersion of new technologies into education and developed an online adaptive educational system Mapwork.education.

Mapwork.education is a web-based, fully automated adaptive learning and assessment system developed in Czech and English language. It is a part of an extensive platform (www.mapwork.education) aiming to help teachers with the systematic development of students' cartographic knowledge and map use skills. The system provides immediate feedback and adapts the further process according to student's performance - simply put, the tasks become more complex/difficult in case of previous correct answer, in the other case the student is given easier tasks. Therefore, the system filters the tasks to be solved and prevents students to solve tasks too difficult/complex or too easy/simple to their actual level of map skills (see Figure 1 for the model of the test administration). The distinction between simple and complex tasks is made based on the typology of map skills (considering map reading as the simplest and map interpretation as the most complex type of map use skills). The system aims at skills related to the use of the most common map types which students use in school and in their personal lives (general reference map, topographic map, choropleth map, proportional symbol map, maps with figural, line, and area symbols), together with less traditional map types (cartogram, dot map, dasymetric map, and isopleth map).

The educational potential of the system (for identification of acquired level of map skills by students and direct development of students' map skills) is strengthen by the by additional educational features for both students and their teachers. The web portal for map education was designed and implemented with gamification elements to facilitate learning efficiency, to boost students' motivation to solve as many tasks as possible, and to develop their map skills more. 


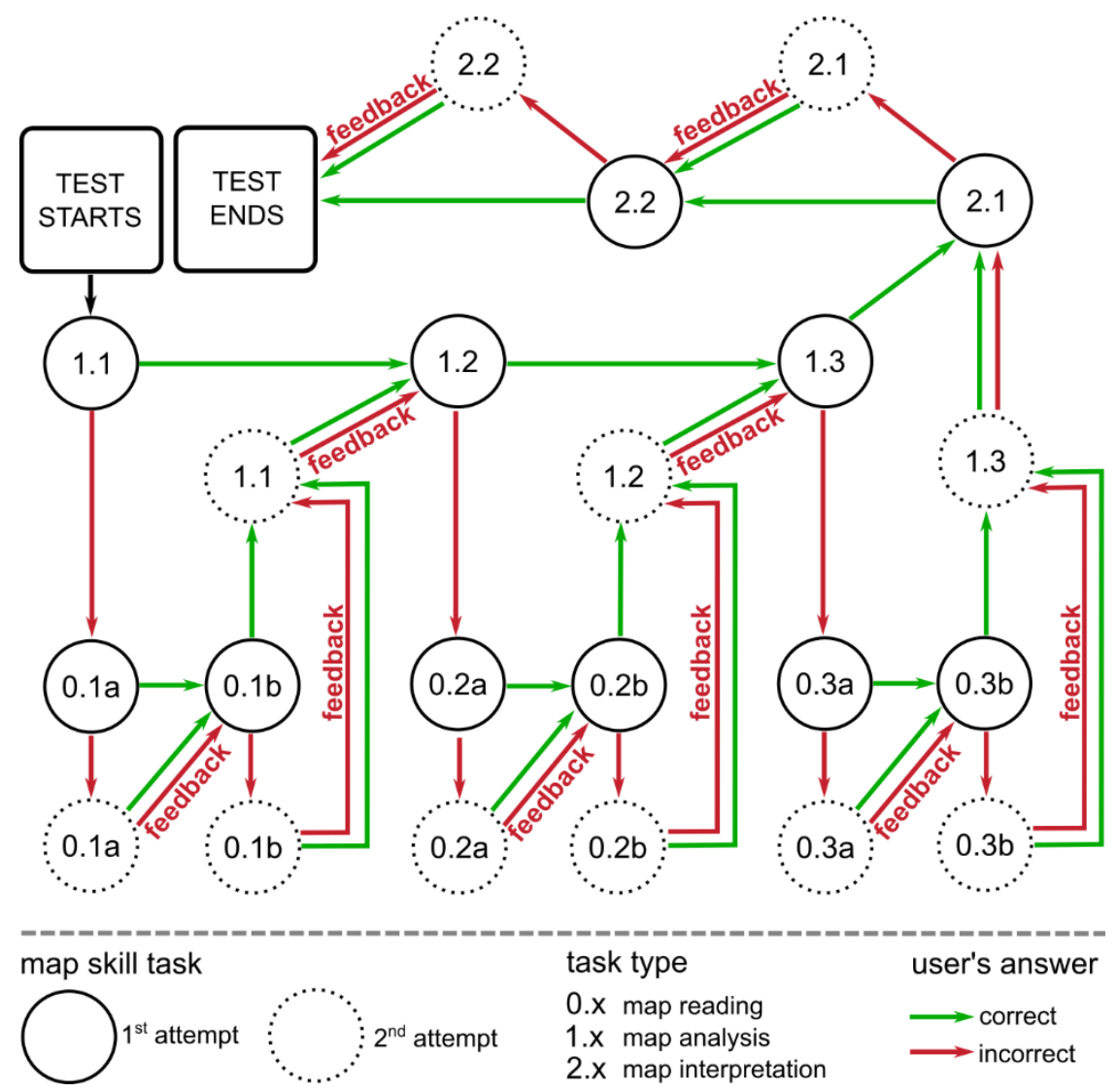

Figure 1. Model of the adaptive test administered in Mapwork.education system (adapted from Hanus, Havelková, in print)

The contribution will present the developed system as a tool supporting a high-quality cartography education. The emphasis will be laid on the discussion of its theoretical principles (adaptive testing principles; cognitive levels of map skills) and the introduction of its methodological/practical aspects. Last but not least, the implications for secondary school cartography will be provided based on the data from the system, specifically data on students' level of map skills (and their improvement thanks to the task solving in the system) and bottlenecks identified in the use of maps by secondary students.

\section{References:}

Hanus, M. and Havelková, L. (in print): Adaptive Assessment of Map Skills. In Bourke, T. and Mills R. (Eds.): Assessment in Geographical Education, Springer. 